\title{
Ensuring that the Sentinel-3A altimeter provides climate-quality data
}

G. D. Quartly, F. Nencioli, S. Labroue, P. Femenias, R. Scharroo, et al.

G. D. Quartly, F. Nencioli, S. Labroue, P. Femenias, R. Scharroo, S. Abdalla, P. Bonnefond, M. Cancet, M.-L. Frery, M. Raynal, S. Baker, A. Muir, D. Brockley, A. Shepherd, P. Garcia, M. Roca, S. Calmant, J.-F. Cretaux, "Ensuring that the Sentinel-3A altimeter provides climate-quality data," Proc. SPIE 10422, Remote Sensing of the Ocean, Sea Ice, Coastal Waters, and Large Water Regions 2017, 104220R (3 October 2017); doi: $10.1117 / 12.2277593$ 


\title{
Ensuring that the Sentinel-3A altimeter provides climate-quality data
}

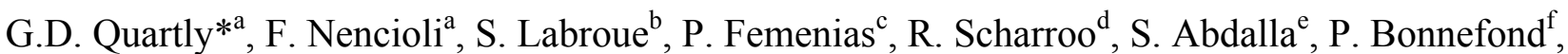 \\ M. Cancet $^{\mathrm{g}}$, M.-L.Frery ${ }^{\mathrm{b}}$, M. Raynal ${ }^{\mathrm{b}}$, S. Baker ${ }^{\mathrm{h}}$, A. Muir ${ }^{\mathrm{h}}$, D. Brockley ${ }^{\mathrm{h}}$, A. Shepherd ${ }^{\mathrm{i}}$, P. Garcia ${ }^{\mathrm{j}}$, \\ M. Roca ${ }^{\mathrm{j}}$, S. Calmant ${ }^{\mathrm{k}}$, J.-F.Cretaux ${ }^{1}$ \\ ${ }^{a}$ Plymouth Marine Laboratory, Plymouth, UK; ${ }^{b} \mathrm{CLS}$, Toulouse, France; ${ }^{\mathrm{c}} \mathrm{ESA}$, Frascati, Italy \\ ${ }^{\mathrm{d}}$ EUMETSAT, Darmstadt, Germany; ${ }^{\mathrm{e}}$ ECMWF, Reading, UK, ${ }_{\mathrm{f}}$ Observatoire de Paris à Meudon, \\ Paris, France; ${ }^{g}$ Noveltis, France; ${ }^{h}$ University College London, UK; ${ }^{i}$ University of Leeds, UK;

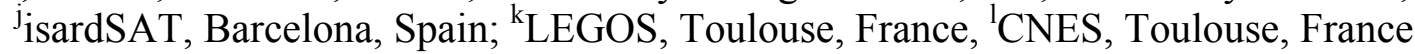

\begin{abstract}
Sentinel-3A, launched in February 2016, is part of ESA's long-term commitment to climate monitoring from space. Its suite of instruments for measuring surface topography includes a Microwave Radiometer (MWR) and SRAL, the first delay-Doppler instrument to provide global coverage. SRAL promises fine spatial resolution and reduced noise levels that should together lead to improved performance over all Earth surfaces. The Sentinel-3 Mission Performance Centre (S3MPC) has been developing the methodology to evaluate the accuracy of retrievals, monitor any changes and develop solutions to known problems.

The S3MPC monitors internal temperatures, path delays and the shape of the generated pulses to assess the instruments health. The MWR records over known reference surfaces are compared with those from other spaceborne instruments. Over the ocean the SRAL's return pulses are analysed to give range to the sea surface, wave height and signal strength (which can be interpreted as wind speed). The metocean data are regularly contrasted with records from in situ measurements and the output from meteorological models, which rapidly highlights the effects of any changes in processing.

Range information is used to give surface elevation, which is assessed in three ways. First, flights over a dedicated radar transponder provide an estimate of path delay to within $\sim 10 \mathrm{~mm}$ (r.m.s.). Second, measurements are compared to GPSlevelled surfaces near Corsica and over Lake Issyk-kul. Third, there are consistency checks between ascending and descending passes and with other missions. Further waveform analysis techniques are being developed to improve the retrieval of information over sea-ice, land-ice and inland waters.
\end{abstract}

Keywords: climate monitoring, Sentinel, altimeter, calibration/validation, sea surface height, cryosphere, inland waters, sea level, ocean dynamics

\section{INTRODUCTION}

The Sentinel series of satellites are the flagship of Europe's plans for long-term monitoring of the Earth, covering both the requirements of immediate weather and ocean prediction services, and the need for long-term homogeneous datasets to improve our understanding of climate variation on the scale of decades. The ambitious programme aims at providing consistent high quality data spanning at least 15 years, which requires the launch of a series of sensors. Sentinel-3A, (S3A) launched on 16th February 2016, is the first of the series imaging the Earth's surface using visible light, infra-red and radar altimetry; a sister spacecraft, Sentinel-3B is due for launch in 2018 to provide greater coverage. Further, nearidentical satellites are expected to succeed these two to enable monitoring for the full 15 years. This paper deals with the assessment of the data quality of the Surface Topography component, principally the radar altimeter, SRAL and the microwave radiometer (MWR).

SRAL is a dual-frequency delay-Doppler instrument ${ }^{1}$, which means that it follows the innovative heritage of Cryosat in that it provides lower noise levels and finer spatial resolution through its SAR-like processing. The existence of the second frequency (C-band in addition to Ku-band) is to help produce better estimates of the ionospheric delay than was possible for the single-frequency Cryosat. The 2-channel MWR, operating at 23.8 and $36.5 \mathrm{GHz}$, is needed to measure the delay associated with moisture in the atmosphere. In addition to the SAR mode processing, the altimeter echoes are 
processed in a way akin to that of conventional altimeters, termed Pseudo Low Resolution Mode (PLRM). A comparison of these two modes of processing is essential in order to establish the continuity of altimetric records between different missions.

The satellite is in a near-circular orbit, with a mean distance above the Earth's surface of $815 \mathrm{~km}$, and an orbit inclination of $98.65^{\circ}$, implying a retrograde orbit that spans the range from $81.35^{\circ} \mathrm{S}$ to $81.35^{\circ} \mathrm{N}$. The orbit has been chosen such that the ground track repeats after 27 days ( 385 complete circuits). Because of the evenness of data coverage, the majority of the analyses detailed in this paper are in terms of these 27-day exact repeat cycles.

\subsection{Data Processing and Assessment}

Data have been collected since the instruments were switched on (at the start of March 2016), with the housekeeping telemetry and the Level 0 data processed on the ground to produce higher-level products. The data are provided with 3 different levels of latency - near real-time (NRT) is within a few hours of collection and is intended principally for the operational agencies, whilst short time-critical (STC) and non-time-critical (NTC) are available after a few days and a month respectively, and have improved values for the corrections and orbits, thus enabling a greater accuracy for climate studies. Data for the marine environment (including sea-ice) are processed and provided by EUMETSAT, whilst the land part (including rivers, lakes and land ice is the remit of the European Space Agency (ESA). They established the Sentinel-3 Mission Performance Centre (S3MPC) to monitor continuously the on-board health of the instruments and the accuracy of the data. A consortium led by ACRI-ST runs the overall S3MPC, with CLS responsible for the surface topography mission, but drawing on the effort of a number of Expert Support Laboratories (ESLs) who have the relevant specialist skills.

During the first 12 months there have been a number of changes to the processing, especially in the SAR processing and the corrections for internal instrumental effects. The key evolutions have been in November 2016 with a new SRAL processing baseline (PB 2.9) that included changes to the Instrument Processing Facilities (IPF 06.07 and 06.05 for Levels 1 and 2 respectively), and a subsequent adjustment of $\sigma^{0}$ (normalized amplitude of return signal). Implementation of PB 2.10, in February 2017, included changes in IPFs for both SRAL and MWR processing. Some of the analysis detailed in this paper focusses on the NRT and STC data and will thus demonstrate the effects of these processing changes; other analyses make use of a reprocessing of the NTC data. Although currently the data mainly circulate within the ESLs who are evaluating them, there was a wider release in Jan 2017 (PB 2.10 for data spanning from Jun. 2016 to Jan. 2017).

\section{INTERNAL MONITORING OF INSTRUMENT PERFORMANCE}

\subsection{Internal monitoring of SRAL}

The SRAL has a number of calibration modes in order to determine the statistics of some key components of the onboard processing. These modes are implemented for a few seconds when the instrument is passing over selected desert regions, so that no data are lost over the ocean or cryosphere. The CAL1 mode produces an attenuated facsimile of the emitted pulse within the receiver chain. This signal is known as the Point Target Response (PTR) and is close to a sinc function; Fig. 1a portrays the amplitude of the secondary lobes for the Ku-band signal, showing that there is a slight asymmetry (with this effect being more pronounced at C-band).

From the regular use of the CAL1 mode, we can consider how some of the parameters of the system are evolving due to ageing (repeated usage) and space exposure. For example the internal time delay is evolving such that the equivalent path length is getting shorter by $1.1 \mathrm{~mm} \mathrm{yr}^{-1}$ (Fog. 2a). Without careful monitoring and compensation this would compromise the ability to measure accurately enough the changes in global mean sea level (currently rising at $3.2 \mathrm{~mm} \mathrm{yr}^{-}$ $\left.{ }^{1}\right)$. The rate of change of emitted power $\left(-0.61 \mathrm{~dB} \mathrm{yr}^{-1}\right.$, see Fig. $\left.2 \mathrm{~b}\right)$ is greater than that noted for Envisat $\left(-0.15 \mathrm{~dB} \mathrm{yr}^{-1}\right)$ or Cryosat $\left(-0.20 \mathrm{~dB} \mathrm{yr}{ }^{-1}\right)$, but the power budget for Sentinel-3 guarantees that data quality should be unaffected for at least the first 5 years of the mission. 

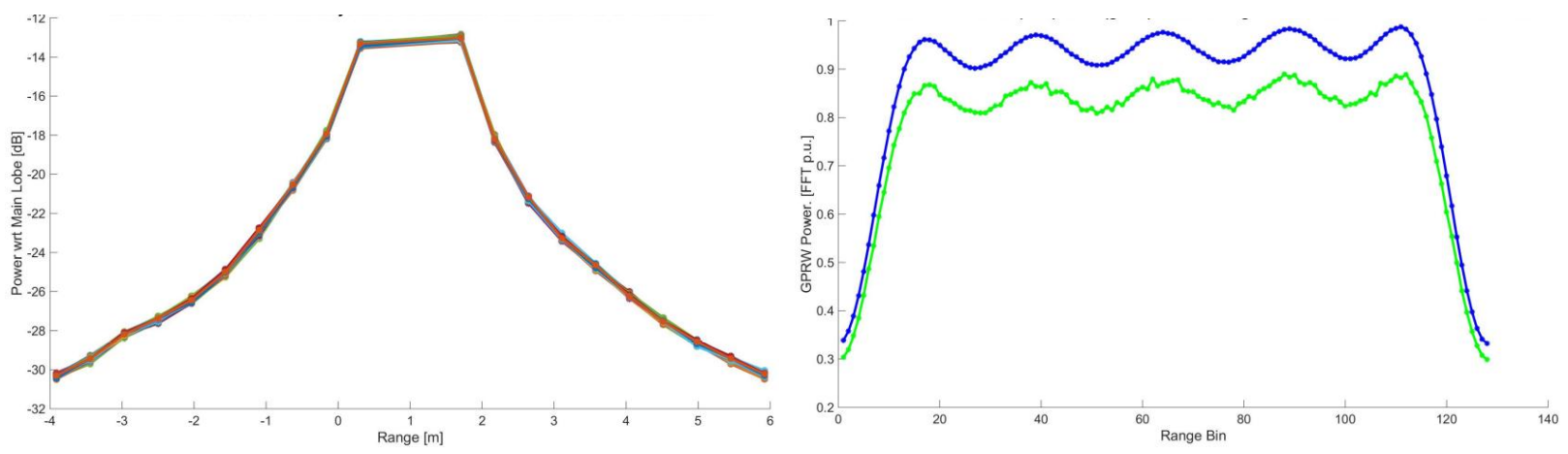

Figure 1. Output of calibration modes during cycle 019. a) CAL1 mode shows height of the sidelobes of the PTR relative to the central peak ( $0 \mathrm{~dB}$, not shown), with $\mathrm{x}$-axis corresponding to range (delay). b) CAL2 shows the system transfer function for $\mathrm{Ku}$-band (blue) and C-band (green).
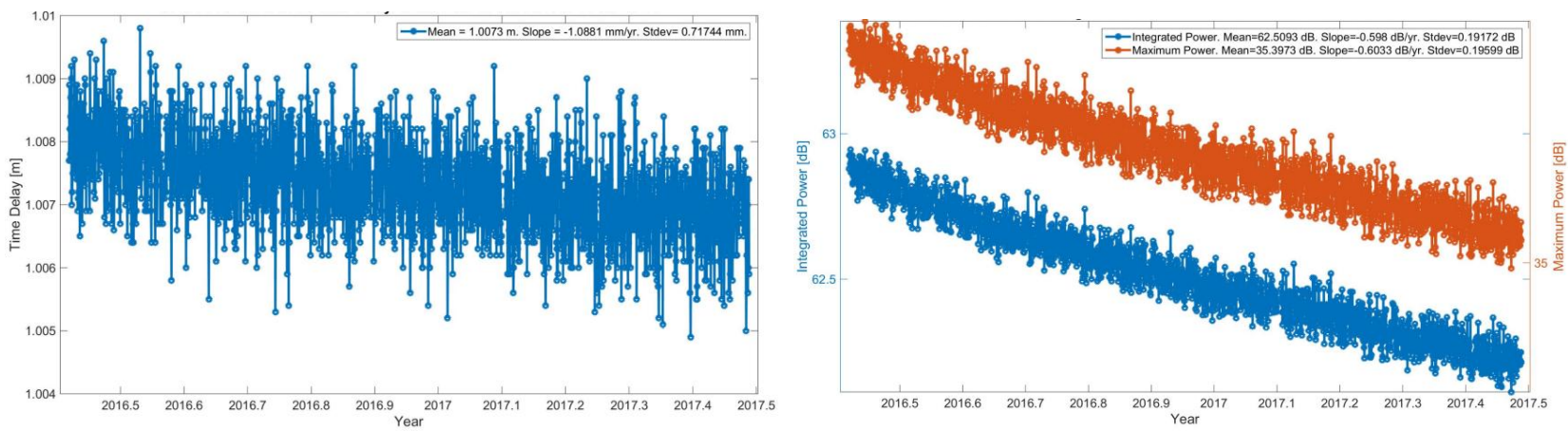

Figure 2. Instrument characteristics derived from the calibration modes for the majority of the mission (Jun 2016-Jul 2017). a) Time delay (given as equivalent distance) b) Intensity of emitted pulse, calculated either from peak of signal (orange) or integrated value (blue)..

The CAL2 mode records the shape of the system transfer function (Fig. 1b) - this is ideally a flat response, but in practice it has ripples along the plateau; however, as long as these characteristics are well known they can be compensated for in the processing. Frequent monitoring shows no appreciable change. The other key internal measure is the frequency of the ulttra-stable oscillator (USO), which controls the timing of pulses and their recorded return. Although this $10 \mathrm{MHz}$ clock has only changed by $0.1 \mathrm{~Hz}$ in the mission to-date (Fig. 3), such a change, if not accounted for, equates to an error in inferred range to Earth of $7 \mathrm{~mm}$.

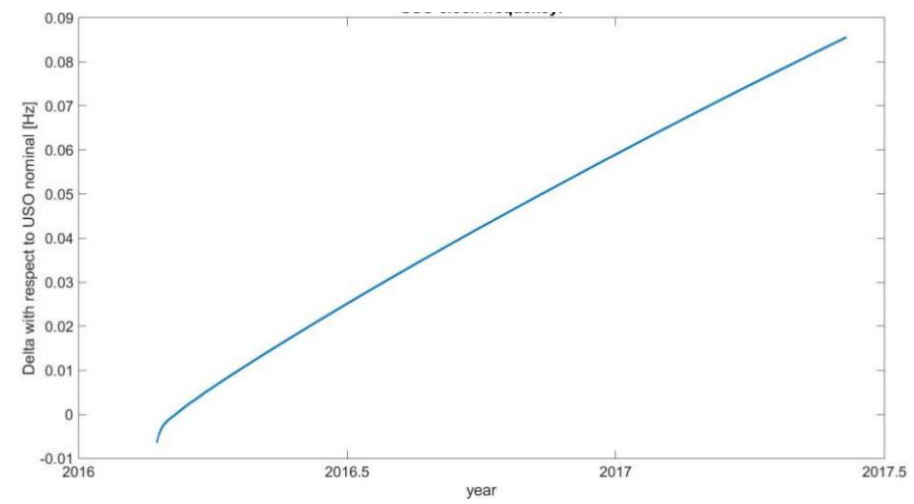

Figure 3. Variation in frequency of Ultra-Stable Oscillator throughout mission. This change in frequency corresponds to $\sim 7$ $\mathrm{mm}$ in range. 


\subsection{Internal Monitoring of MWR}

The MWR operates as a balanced Dicke radiometer for microwave emissions lower than the internal reference load. The balance is achieved by the injection of noise with a noise diode (NIR). When the received emissions are higher than the internal reference, then a conventional Dicke mode (Dicke Non-Balanced) is used. The noise injection is the main operating mode of the MWR as brightness temperatures strong enough to exceed the internal temperature occur rarely, and this only occurs over land and for the $36.5 \mathrm{GHz}$ channel. These internal calibration parameters have to be monitored to ensure stability: the key parameters are the noise injection temperature (NIR) and the gain (DNB) i.e. the constant of proportionality. Fig. 4 shows the noise injection temperature at the MWR's two frequencies, with the blue lines on the left showing the results of a reprocessing (IPF 06.05) of the early cycles, and the turquoise lines on the right are from the more immediate NRT chain and correspond to processing up to v6.11. After a marked change during the first two 27day cycles, the values at $23.8 \mathrm{GHz}$ have remained very stable, with only a slight decrease since cycle 13 (Jan. 2017), whereas those for $36.5 \mathrm{GHz}$ channel show more pronounced variations.
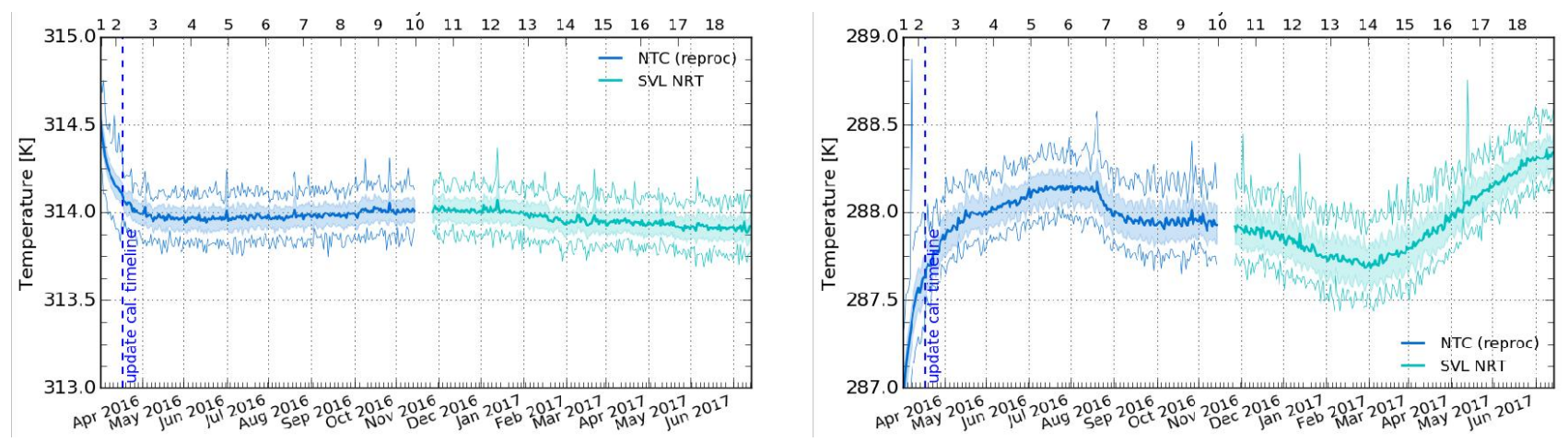

Figure 4. Monitoring of noise injection temperature in MWR for (left) $23.8 \mathrm{GHz}$ and (right) $36.5 \mathrm{GHz}$.. Cycle numbers are provided at the top. The dark central line indicates the daily mean of the measurements, with the lighter lines showing the minima and maxima, and the shading indicating \pm 1 std. dev.

An important assessment of the consistency in performance is achieved by contrasting the observations obtained separately by ascending and descending passes (Fig. 5). The ascending tracks correspond to daytime passes when the satellite is within full sunlight, and the descending passes are night-time observations, when it is in eclipse. Direct comparison is not possible because orbit crossovers may correspond to several weeks' difference between the ascending and descending observations, during which atmospheric conditions will change. For this assessment, we use the single difference i.e. the difference between measurements and values simulated by a model. There should not be a significant mean bias between the ascending and descending single difference over the ocean. If there is such a bias, it suggests some sensitivity to the satellite's exposure to solar radiation.
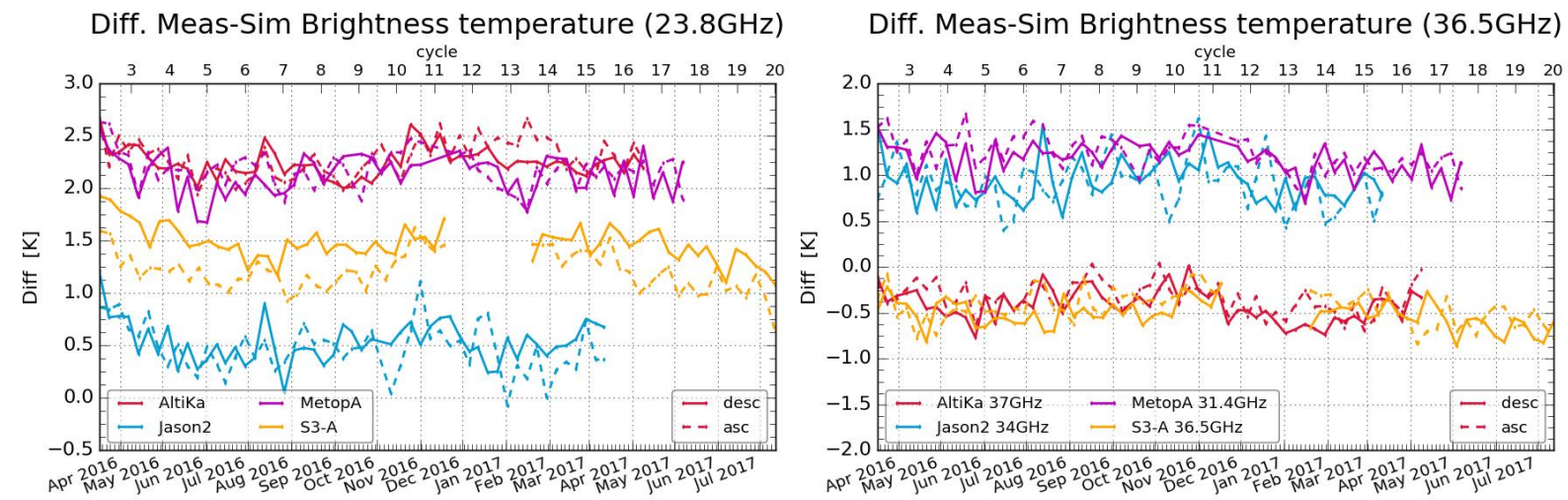

Figure 5. Comparison of recorded brightness temperatures with respect to a model for (left) $23.8 \mathrm{GHz}$ and (right) $36.5 \mathrm{GHz}$ with the colour of the lines indicating the different sensors, and the line style (solid and dashed) showing the differences for descending and ascending passes respectively. 


\subsection{MWR monitoring using reference surfaces}

Certain parts of the Earth's surface provide nearly constant microwave emissions; monitoring of the MWR data over two such targets spanning the range of credible brightness temperatures helps confirm the correct relationship for converting Level 0 data into brightness temperatures. The cold reference is the coldest part of the ocean, which is determined by a statistical method proposed by Ruf ${ }^{2}$. The hot reference is provided by a section of the Amazon Forest that has been classified as "evergreen forest" in the GlobCover classification scheme ${ }^{3}$. Such an area acts as an almost perfect black body at the microwave frequencies of interest.

The results are displayed here for $36.5 \mathrm{GHz}$, along with the performance of other radiometers in their respective liquid water channels. Note that the recorded brightness temperatures over the cold ocean site show a weak dependence on the measurement frequency, with S-3A's channel being a little less than AltiKa (37 GHz) but higher than Jason-2/3 (34 GHz) and AMSU on Metop-A (31.4 GHz). Consequently consideration must be given to the stability of the time series as much as the precise value.

Marked changes are noted in the S-3A STC product for the cold reference (Fig. 6a) in response to the changes in the characterization files and processing issues (indicated by dashed lines in Dec. 2016 and Jan. 2017), but there was no effect at the hot reference. The cold reference site provides near constant records for all radiometers, with the actual values being clearly separated according to frequency. At the hot site there is no obvious separation with frequency (because the forest is acting as a black body), but there is a secular variation for all radiometers, with peaks around Mar. and Dec. 2016. From such a short time series (especially with these secular variations), it is not possible to determine whether there is any drift in the S-3A MWR.
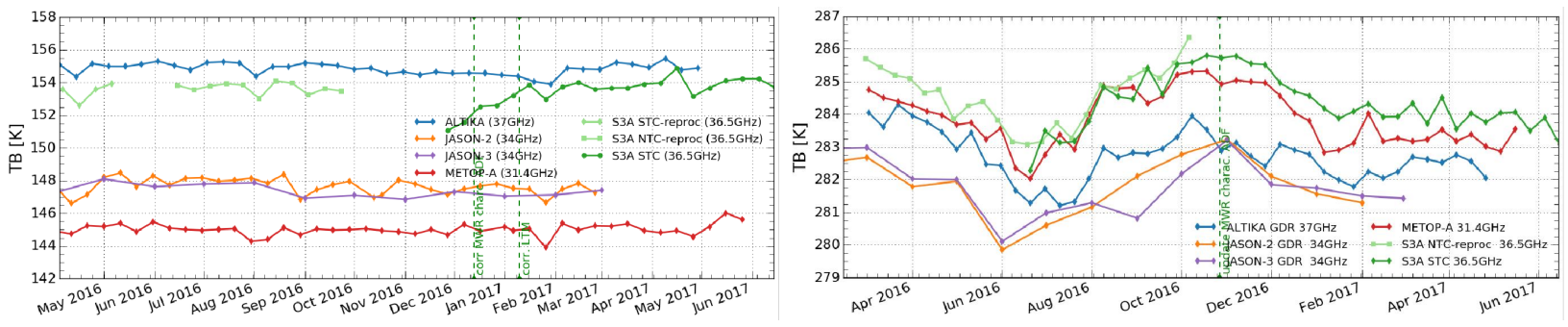

Figure 6. Monitoring of the liquid water channel of various different radiometers records over (left) cold ocean reference and (right) Amazon Forest hot reference. The dark green line shows the record for the S-3A STC product using whichever processing stream was current, whereas the lighter green line in the left half of each plot shows a subsequent reprocessing (NTC) with v6.05. The vertical dashed lines in Dec. 2016 and Jan. 2017 represent when changes occurred in the MWR processing chain.

\section{ASSESSMENT OF METOCEAN AND ATMOSPHERIC RETRIEVALS}

\subsection{Validation of wind and wave data with in situ sensors}

The measure of signal strength of the altimeter return, $\sigma^{0}$, is converted to wind speed using a universal algorithm for all instruments ${ }^{4}$. These records for wind speed and significant wave height (SWH) are then matched up with nearsimultaneous in situ measurements (principally buoys, but also some fixed platform and ship records). The altimeter data are averaged over $11 \mathrm{~s}$ along track ( $75 \mathrm{~km}$ distance) and the match-up requirements are quite broad (within $200 \mathrm{~km}$ and 2 hours) in order to allow sufficient comparisons in a small time, but with the restriction that the model values at the altimeter and the in-situ locations are not too different from each other in order to ensure that both measure the same part of the weather system, at least as seen by the model.

The results (in Fig. 7) show a clustering about the line of unit slope, with a greater spread for the wind speed: the standard deviation of the differences is $\sim 18 \%$ of the mean value, whereas it's only $12 \%$ for SWH. The mean relationship (indicated by the ' $\mathrm{X}$ ' and ' $\mathrm{O}$ ' symbols on the plots) shows that S-3A is underestimating wind speed at moderate values (5$10 \mathrm{~m} \mathrm{~s}^{-1}$, see Fig. 7a), whereas the SWH estimates diverge from the in situ more at high values (Fig. 7b). However, it should be remembered the locations of these observations are not representative of the whole globe, with most of the 
available meteorological buoys situated in coastal environments in the northern hemisphere (chiefly around Europe and the US).
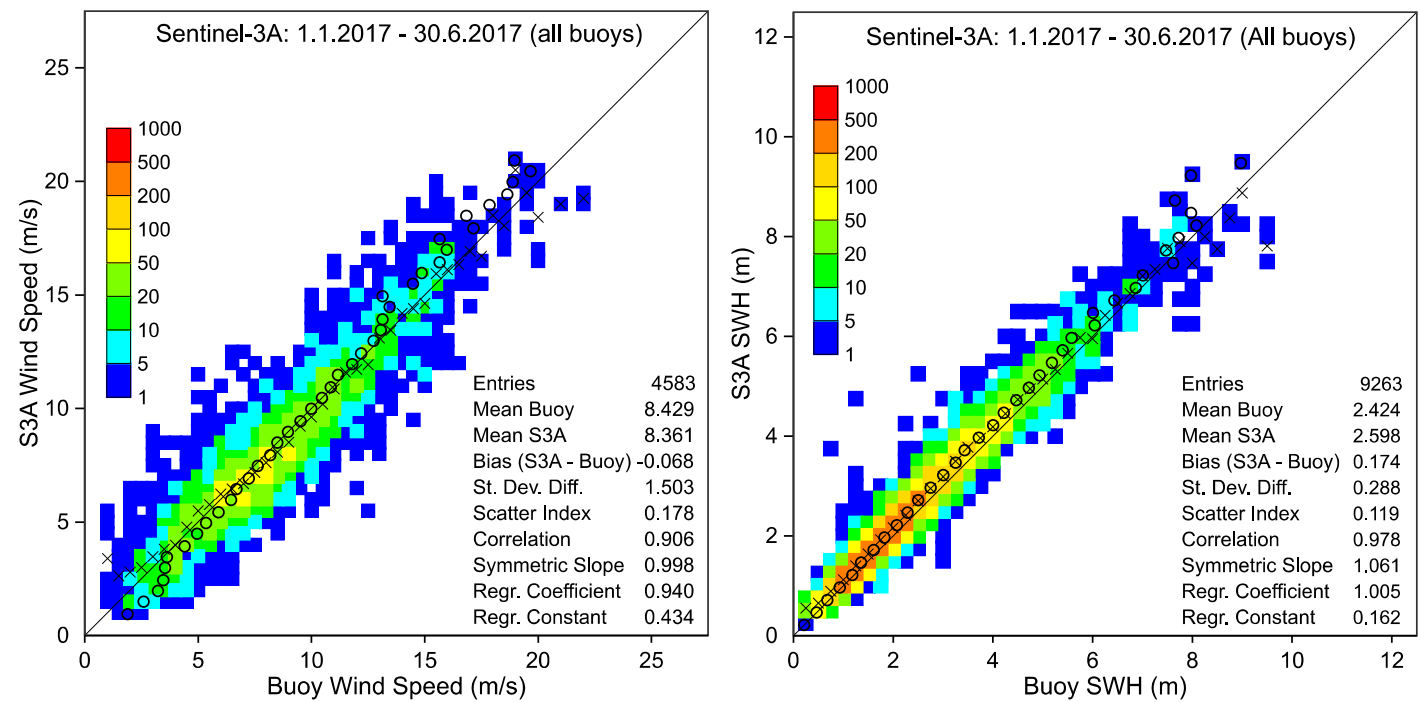

Figure 7. Scatterplot showing comparison of (left) wind speed and (right) wave height data from Sentinel-3A with meteorological buoys. The colour indicates the number density of matchups, with a logarithmic scaling. The period analysed is the 6 months from January to June 2017, with the mean biases of the S-3A data being $-0.07 \mathrm{~m} \mathrm{~s}^{-1}$ and $0.17 \mathrm{~m}$ respectively, with the standard deviation of the anomalies being $1.50 \mathrm{~m} \mathrm{~s}^{-1}$ and $0.29 \mathrm{~m}$.

\subsection{Validation of wind and wave data with model output}

Comparison with the output from accurate numerical models provides a means to overcome the limitation of the in situ analysis. Models can provide global coverage and thus many more match-ups than the satellite observations, and their range of conditions should be representative of the whole ocean, rather than being dominated by coastal observations in the northern hemisphere. But such comparisons are specious unless the models used do provide a good realization of the real world situation. For the wind speed analysis we use ECMWF's Integrated Forecasting System (IFS), which is a comprehensive atmospheric forecasting-system that simulates the dynamics, thermodynamics and composition of the Earth's fluid envelope and interacting parts of the Earth system. IFS includes a sophisticated data assimilation system based on 4D-VAR that allows the assimilation of a vast amount of atmospheric data. It uses a horizontal grid with $\sim 9$ $\mathrm{km}$ spacing and 137 layers to discretize the atmosphere. Dedicated studies show that the wind speed at 10-m height (also referred to as "surface wind") is accurate to within $0.8 \mathrm{~m} \mathrm{~s}^{-1}$. The wave data are compared against the short forecasts from the wave model, WAM, which is one of the IFS components. The short forecast is used rather than the model analysis (which is the best model representation of the atmospheric state), since the latter assimilates wave height data from a number of other current altimeters.

The model comparisons use the same altimetry processing as for the in situ comparisons (i.e. 11-second averaged "superobservations"), and these permit a 100-fold increase in the number of comparisons (see Fig. 8); this can be especially useful in evaluating the algorithms for Sentinel-3 data for the high wind speed, large wave height conditions that are infrequently sampled by coastal buoys.

Mapping of the anomalies (satellite minus model) reveals that S-3A wind speeds are in very good agreement with the model almost everywhere. Some relatively high deviations of up to $0.6-1.0 \mathrm{~m} \mathrm{~s}^{-1}$ occur in regions with large-scale surface currents especially the equatorial currents. For wave height, the satellite record has fewer observations than the model near the mode of the p.d.f. (1.5-2.5m), but provides a higher count of high wave conditions. A mapping of the anomalies shows S-3A to be biased high nearly everywhere, but with a greater disparity in the locations of large waves between $40^{\circ}$ and $55^{\circ} \mathrm{S}$. 

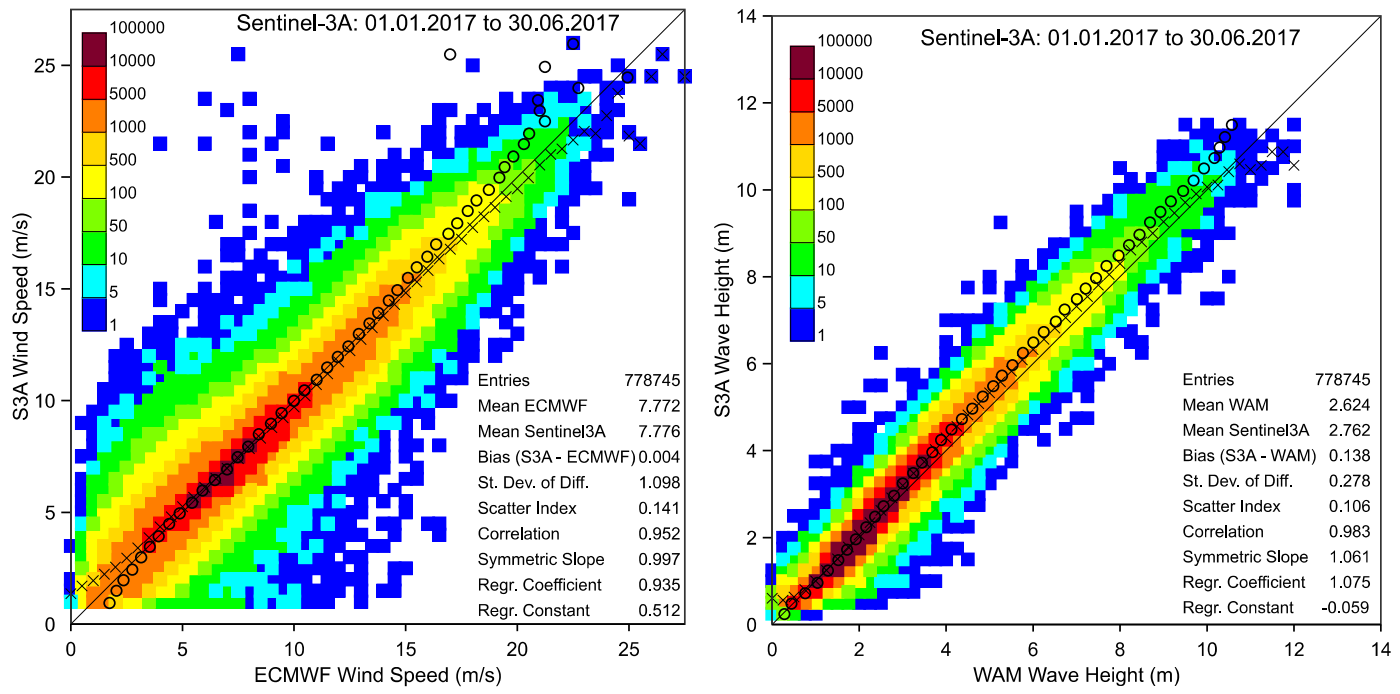

Figure 8. Scatterplot showing comparison of (left) wind speed and (right) wave height data from Sentinel-3A with model output. The colour indicates the number density of matchups, with a logarithmic scaling. The period analysed is JanuaryJune 2017, with the mean biases of the S-3 data being $0.00 \mathrm{~m} \mathrm{~s}^{-1}$ and $0.14 \mathrm{~m}$ respectively, with standard deviation of the anomalies being $1.10 \mathrm{~m} \mathrm{~s}^{-1}$ and $0.28 \mathrm{~m}$.

\subsection{Assessment of changes in processing}

During the preceding 12 months there have been a number of evolutions of the processing chain. As the NRT data are always produced with the then current processing baseline, the effect of these changes can be seen in the global mean anomalies (Fig. 9). There was an initial release of the data for April 2016, but then a hiatus with NRT processing being recommenced in late June. The major change in biases is associated with the introduction of v6.05 of the processing in early Dec. 2016. Of course, care is required to understand whether there are any relevant changes in the operational models used for these comparisons, and what is their impact.
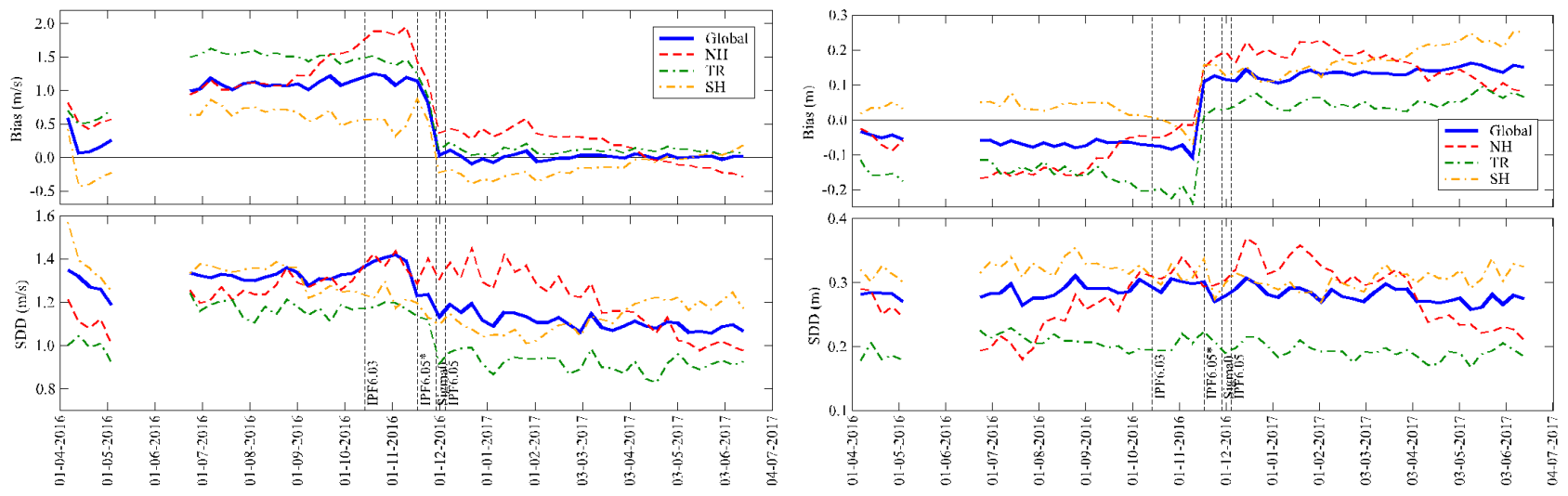

Figure 9. Time series showing bias and S.D. of differences for Sentinel-3 data relative to model for (left) wind speed and (right) wave height. Each line represents a 7-day moving average of the comparisons. These plots show the anthology of NRT data since the start of the mission, with a number of the key processing changes marked. The separation into averages for Northern Hemisphere $\left(\mathrm{NH}, 20^{\circ}-80^{\circ} \mathrm{N}\right)$, Southern Hemisphere ( $\left.\mathrm{SH}, 20^{\circ}-80^{\circ} \mathrm{S}\right)$ and Tropics $(\mathrm{TR})$ shows that some of the bias may vary with season.

Interpretation is also complicated by the seasonal cycle in the wind and wave fields such that if a dataset is only biased high in large SWH conditions, then it will show temporal variations associated with the change in storminess between summer and winter conditions. Thus although there are long-term coherent differences between the mean for the two hemispheres, this may be an artefact of changing conditions rather than regional biases in the algorithms. The lower plots show the standard deviation of the differences. For wind speed, the reduction in overall S.D. in Nov. 2016 appears 
to be solely due to an improvement in S-3A data in the tropics, although this may reflect an improved recovery in lowwind regimes. For wave height, the change in bias in Nov. 2016 is not accompanied by a reduction in S.D.

\subsection{Assessment of MWR-derived atmospheric parameters with model output}

The MWR is used to provide accurate estimates of the atmospheric water vapour and the columnar liquid water, both of which have an effect on the progression of radar waves. These are used to calculate the extra delay of the signal, known as the Wet Troposphere Correction (WTC), and the atmospheric attenuation, which reduces the intensity of the backscattered signal and thus affects wind speed estimates. These two corrections can also be estimated from the ECMWF model analysis; although the model will not be able to resolve the finer scale weather features, it once again provides a reference that is roughly consistent with the values from other radiometers.
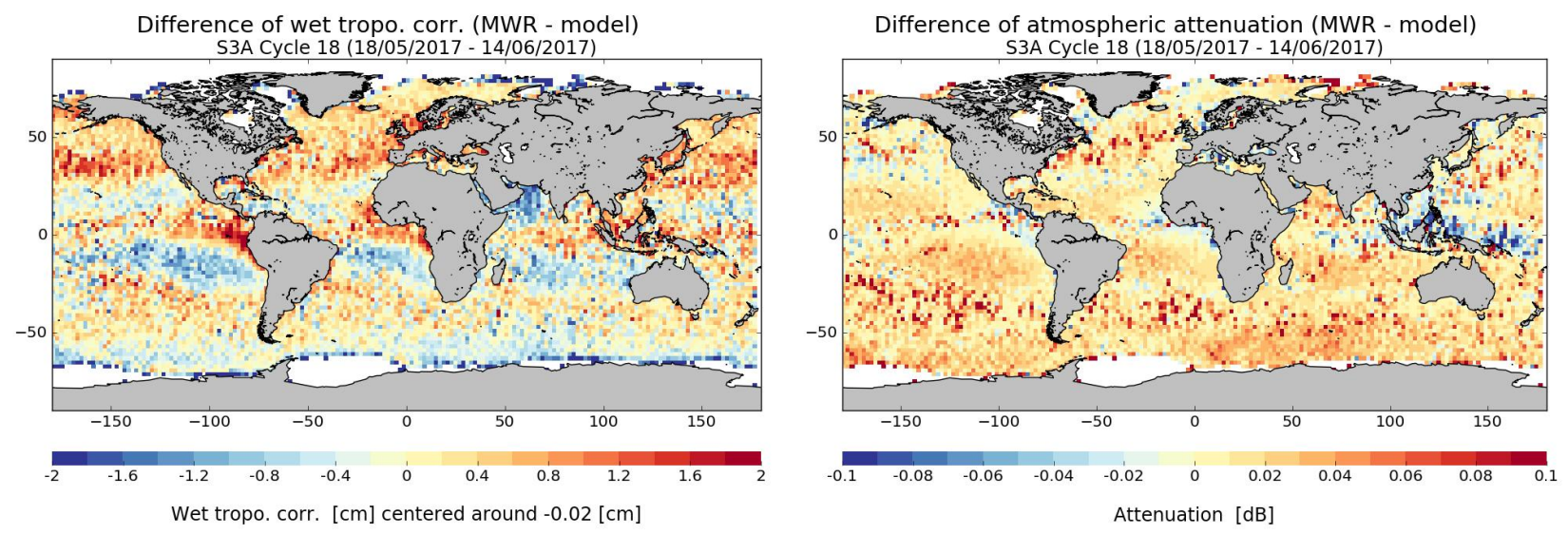

Figure 10. Mapped differences between MWR-derived values and those derived from ECMWF model. (left) wet tropospheric correction; (right) atmospheric attenuation.

A p.d.f. of the differences in WTC for MWR relative to model has a mean near zero and a S.D. of $1.4 \mathrm{~cm}$ (not shown), but there is strong regional coherence in the location of the patterns (Fig. 10a), with the satellite appearing to overestimate at the eastern end of each tropical ocean and underestimate in the drier bands either side of the ITCZ. However, a similar analysis for the Jason-3 radiometer shows the same patterns, but with a slightly weaker amplitude $(\mathrm{S} . \mathrm{D} .=1.2 \mathrm{~cm})$. The smaller errors for Jason-3 are likely due to it having a 3-channel radiometer, but the common geographical patterns suggest either that there may be errors in the way the model represents certain aspects of the water cycle, or that there is a common misconception in the radiative model used for the inversion of various MWR datasets. The comparisons for atmospheric attenuation show that the MWR overestimates (relative to the model) by $0.02 \mathrm{~dB}$, and that there are not such clear geographical patterns (Fig. 10b).

\section{DETERMINATION OF RANGE BIAS}

To combine sea surface height (SSH) data from multiple instruments, it is essential to understand and measure any bias in the measurement of range, whether the purpose is for combining data from contemporaneous altimeters to better map the mesoscale field, or sequential sensors to establish a long-term consistent climate record.

\subsection{Analysis of transponder data from Gavdos}

A radar transponder is an active instrument that detects and records a radio-wave signal, such as a pulse from an altimeter, and sends back a copy of the signal with a well-calibrated time delay and amplification. Because of the significant amplification the pulse "reflected" from such a device will dominate over that from all passive surfaces. So, for an altimeter transit over a transponder, many of the signals recorded on-board will have a simple pulse shape, with position dictated by the distance to the transponder. From this series of signals one can determine the effective distance to the altimeter at closest approach, and compare the inferred surface elevation to a very precise GPS determination of its 
position to give a "range bias", which is usually assumed to account for errors in determination of the radar path length within the satellite. To provide as accurate an estimate as possible, precise measurements are also required for the atmospheric delay terms and a good model for the Earth tide. The timing of nearest approach is contrasted with the supposed orbital position to infer the error in the on-board clock, know as the "datation bias".

A transponder facility has been established at Gavdos, south of Crete and used to determine the biases of Envisat, Jason1 and Jason- $2^{5}$; it has now been further developed for calibration of Sentinel- $3^{6}$. It is in a well-surveyed location on an open hillside, and the facility also includes instrumentation for measuring the atmospheric delay terms through radiometry. The processing to determine the nearest approach requires the waveform data that are available in an earlier lower level product. At present, not all altimeter overflights have been analysed, but from 12 such transits (see Fig. 11) we find the mean range bias to be $6.3 \mathrm{~mm}$, with a S.D. of $10.5 \mathrm{~mm}$, and the datation bias has a mean of $-155 \mu \mathrm{s}$ (which is consistent with other approaches) and a S.D. of $33.2 \mu \mathrm{s}$.

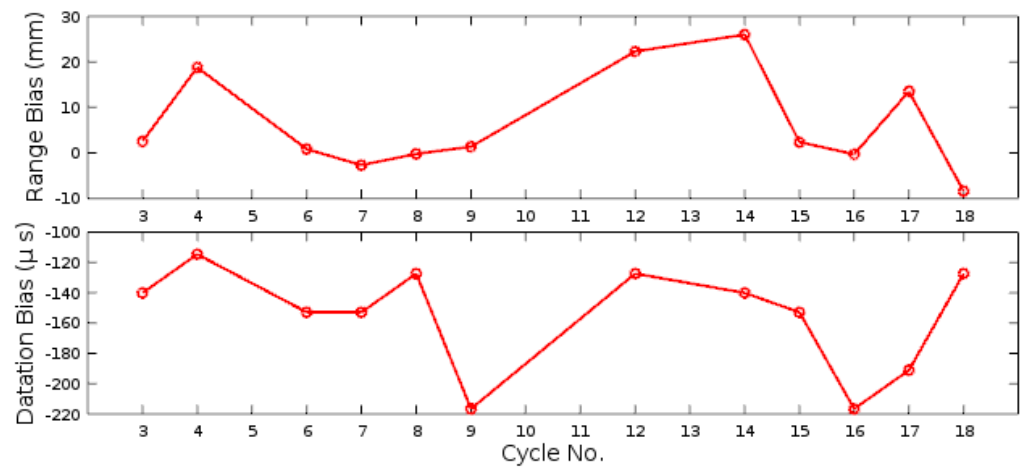

Figure 11. Transponder analysis has been carried out for 12 overflights to-date. (top) Range bias (bottom) Datation bias.

\subsection{Analysis of marine data southwest of Corsica}

An alternative way to estimate the range bias within the altimeter is to use reflections from a water surface whose elevation is known precisely within the same reference framework. This should be in a location of minimal waves (so that sea state bias is not a concern) and tides and the local mean sea surface should be well known. The southwest corner of Corsica is a region that has been used for absolute range calibration for decades. First, the TOPEX/Poseidon/Jason tracks intersect the coast at Senetosa, and second, Envisat and AltiKa (when either was in the 35-day exact repeat cycle) had a track that exited the land at Ajaccio. Sections of both these tracks near the coast have been thoroughly surveyed with GPS sensors (see Fig. 12a). Sentinel-3A ascending pass 741 overflies the Senetosa area and $\sim 5 \mathrm{~s}$ later the Ajaccio one. It allows us for the first time to compare the biases in sea surface height (SSH) obtained at both locations, which are completely independent in terms of geodetic references and also in terms of in situ measurement systems.

For the present analysis we access a homogeneous set of data by combining reprocessed NTC data for cycles 5-10 (JunNov 2016) with more recent STC/NRT data with effectively the same processing. For all these products we have analyzed and compared SSH values derived from the 2 processing modes (SARM and PLRM). For each cycle, we have averaged the independent SSH biases from Senetosa and Ajaccio, and the time series is presented in Figure 12. It shows that the bias for SAR is very stable with a standard deviation of $18 \mathrm{~mm}$ (about half the typical value for Jason). Concerning the PLRM, the standard deviation of $28 \mathrm{~mm}$ is of similar magnitude to classical LRM missions (e.g. Jason). The $21 \mathrm{~mm}$ difference in the SSH bias between SARM and PLRM comes mainly from range (17 $\mathrm{mm}$ from orbit-range statistics). Thus, from the 10 currently available repeat passes off southwest Corsica, we conclude that SSH bias for Sentinel-3A is $+11 \pm 6 \mathrm{~mm}$ and $-10 \pm 9 \mathrm{~mm}$ for respectively SAR and PLRM. 

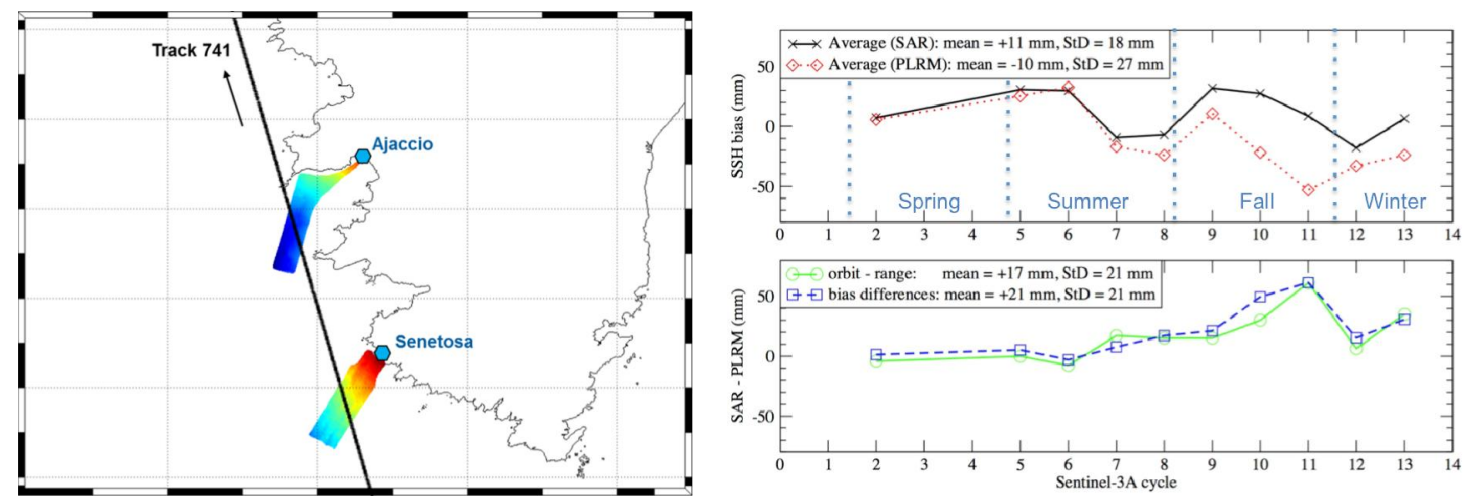

Figure 12. (left) Sentinel-3A track 741 passes over 2 Corsican sites (Senetosa and Ajaccio) that have already had their mean sea surface surveyed by GPS (for Jason and Envisat/AltiKa missions respectively). (right) Plot of the averaged SSH bias from Ajaccio and Senetosa stations for the 10 cycles processed to-date.

\subsection{Analysis of overflights of Lake Issyk-kul}

A very different comparison is provided by the S-3A overflights of Lake Issy-kul in Kyrgyzstan. It is the second largest mountain lake in the world, with an altitude of about $1600 \mathrm{~m}$ above mean sea level. As it is a confined water body in a region between two mountain ranges, there is no swell, and locally-produced wind waves are minimal; therefore sea state bias can be ignored. Its location also means that there are no tides, seiche bahaviour or any response to changes in atmospheric pressure.. A number of S-3A tracks cross the lake, with two of interest (nos. 666 and 707) recording clear water surface echoes for over $40 \mathrm{~km}$ (see Fig. 13a). These 2 tracks are surveyed at each time of overflight by a small research vessel recording both the position of its GPS sensor and the range from that sensor to the lake surface (which will of course change with loading).

The analysis performed to-date has looked at the performance of two different retrackers: SAMOSA (the ocean retracker) and OCOG (which is often used over land ice). Figure 13b shows the results for the SAMOSA retracker, which mainly show a smooth variation in lake level (relative to the reference ellipsoid), except for greater variability at the edges where the intrusion of land reflections into the return echoes affect the derivation of range. A similar analysis using the OCOG retracker (not shown), which is commonly applied over ice surfaces, revealed a bias between the two retrackers of order $80 \mathrm{~cm}$.
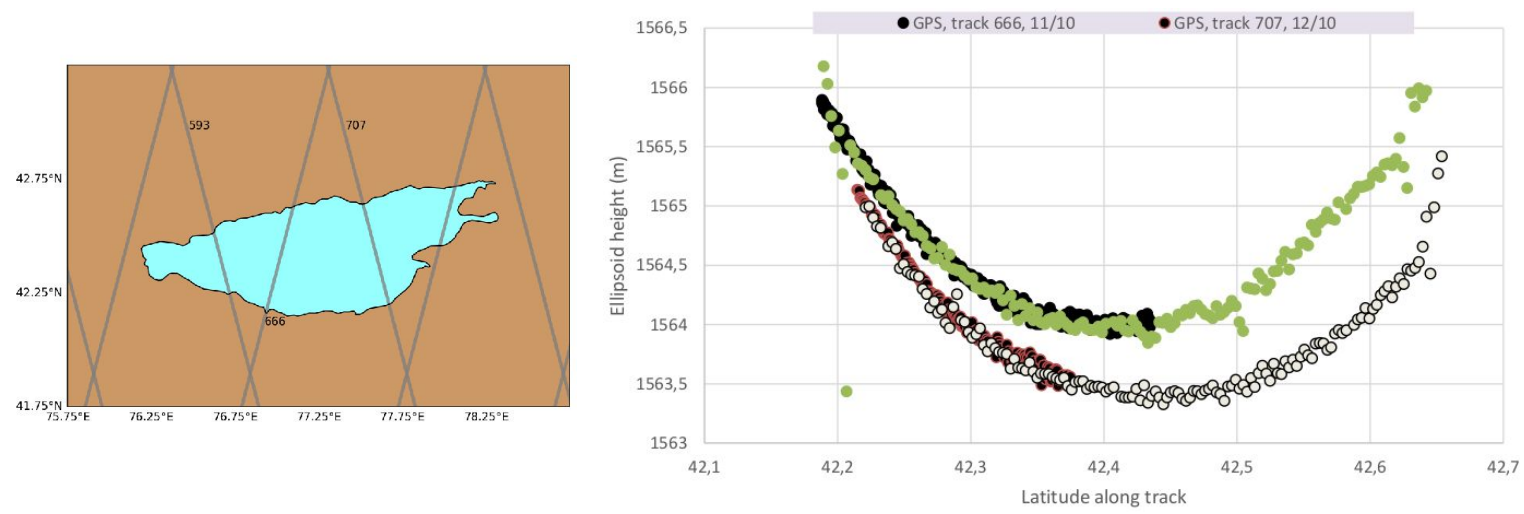

Figure 13. (left) Map of Lake Issyk-kul with key S-3A passes indicated. (right) Height data from 2 passes referenced to the ellipsoid. The green and white circles are the heights derived from S-3A using the SAMOSA retracker; the black and brown circles are from the shipborne GPS survey that only covered part of the altimeter transit. 


\section{QUALITY ASSESSMENT OF LEVEL 2 MARINE DATA}

Several of the preceding sections have dealt with aspects of the error budget e.g. internal instrumental bias and atmospheric correction terms. This section examines the overall product, showing in what aspects it is consistent with other missions, and in which ways it sets new standards.

\subsection{Noise level of spectra}

One evaluation of the end-to-end performance is to examine the noise level of the derived sea surface height (SSH) records. A spectral analysis of the along-track SSH profiles will usually have a $\mathrm{k}^{-\mathrm{n}}$ form in the $50-500 \mathrm{~km}$ domain, describing the real world variations in the sea surface elevation associated with mesoscale features, although the slope of the spectra may vary with geographical region? ${ }^{7}$. At very short spatial scales the spectra will be dominated by measurement noise, which is a property of the measuring system (altimeter instrument and corrections). The lower the noise floor, the better the measurement system will be able to resolve smaller scale geophysical features. Figure 14a shows that the SAR mode processing for S-3A has a noise level of $5.47 \mathrm{~cm}$, which is almost half that achieved by PLRM processing $(10.87 \mathrm{~cm})$. In this respect, the Sentinel-3 system outperforms Jason-3 $(7.72 \mathrm{~cm})$ even though the latter has a better orbit for high precision altimetry. The conventional altimetry processing for Jason-3 (LRM) and Sentinel-3A (PLRM) also produce a "spectral bump" around 10-30 km, which has been associated with the size of the altimeter's footprint $^{8}$. A similar measure of intrinsic variability is the standard deviation of the 20 (altitude-range) values contributing to the $1 \mathrm{~Hz}$ record - this provides a measure of performance of the altimeter without the corrections???. This indicator, termed $\sigma_{\mathrm{h}}$, increases with wave height, as the location of the mid-power on the leading edge becomes less constrained when this edge become less steep. SAR mode processing again achieves a noise level about half that of S3A'a PLRM and also noticeably less than Jason-3 too (Fig. 14b).
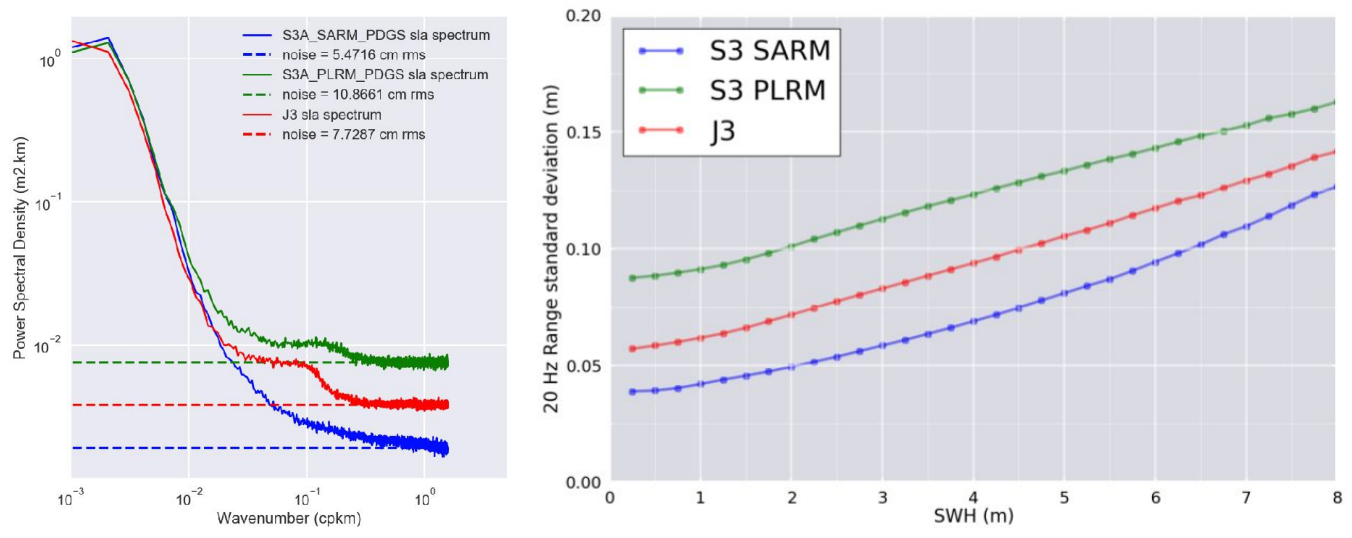

Figure 14. (left) Spectra from SSH profiles, contrasting results for Sentinel-3A (both SAR mode and PLRM) with Jason-3. (right) Plot of S.D. of $20 \mathrm{~Hz}$ SSH values within each 1-second record as a function of SWH.

\subsection{Mapped sea level and wave height}

A second evaluation is as to whether the S-3A records are consistent with those from other altimeters such that they can be usefully combined for mapping, and that their time series may be collated to provide consistent climate data records. Figure 15 compares the records of sea level and wave height from Sentinel-3A and Jason-3. There is a very strong correspondence between the maps of sea level anomaly. [Note that the global mean values of SLA have been removed from each dataset prior to plotting; the SSH records for S-3A are currently biased high by $0.07 \mathrm{~m}$ relative to Jason-3, but such an offset may disappear in later S-3A products.]

The broad patterns of wave height agree between the two sensors. However, for both instruments individual tracks appear prominent, due to the non-synoptic sampling of a wave field that may change rapidly in response to storms. Figure 16 provides a long-term view of the consistency, characterizing the wave field simply by the mean value. With that degree of spatial averaging, the temporal agreement of S-3A and Jason-3 is very clear. There is a consistent offset of $0.21 \mathrm{~m}$ between the two versions of the S-3A data (SAR mode and PLRM), with the Jason-3 time series of SWH 
being $0.09 \mathrm{~m}$ below that of S-3A SAR mode processing. Evolutions of the processing chain are being considered, which will take into account a better understanding of the SAR processing, and these may reduce the offsets relative to Jason-3 and to models and in situ (see Sect. 4).
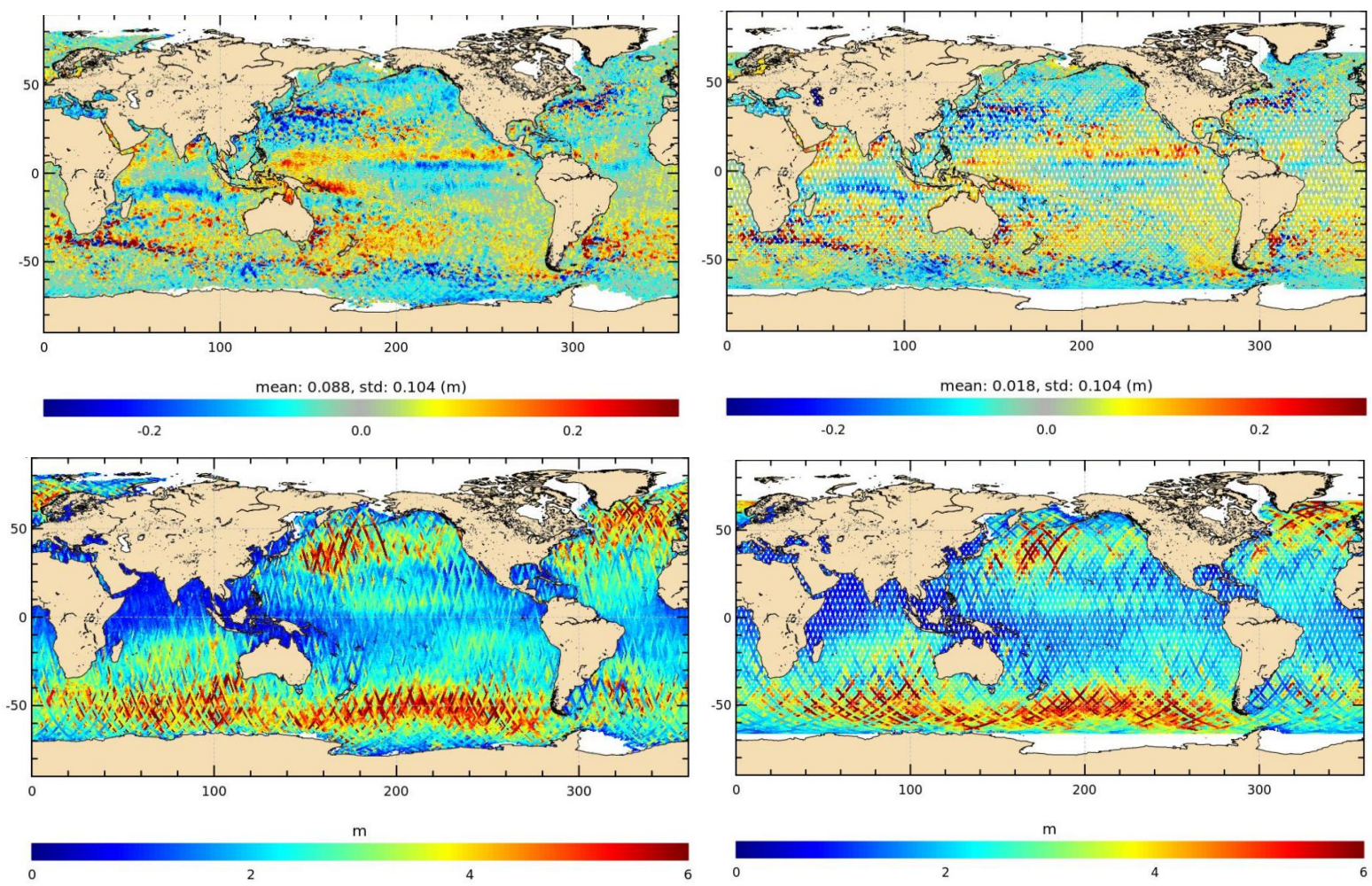

Figure 15. A comparison of the mapped fields produced using either Sentinel-3 data (left-hand side) or Jason-3 data (righthand side). The top row shows Mean Sea Level Anomaly, whilst the bottom row shows Significant Wave Height. [Period analysed is 25th Apr.-23rd May (corresponding to S-3A cycle 015) for both missions.]

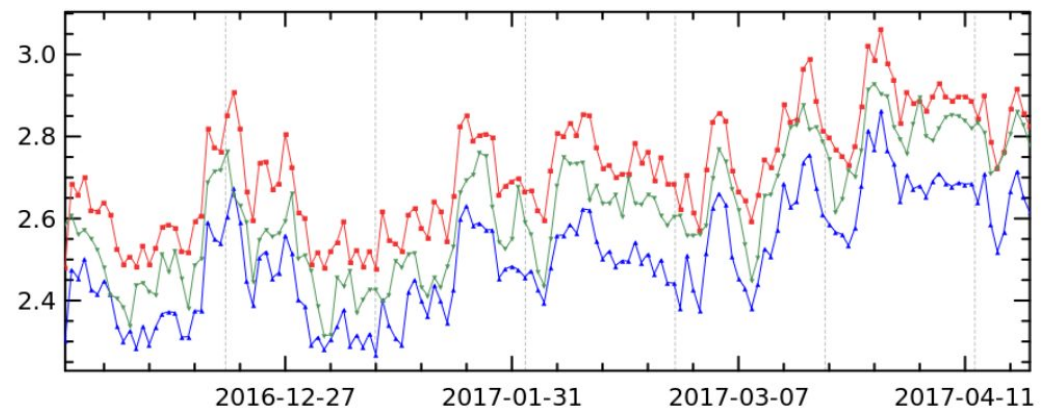

Figure 16. Time series of mean SWH throughout the mission, for S-3A SAR processing (red) and PLRM (blue). The time series for Jason-3 (green) are provided for comparison..

\section{ALTIMETRY OVER NON-MARINE SURFACES}

The Sentinel-3 altimeter is in operation over all surfaces day and night. Although the original radar altimeters were designed for operation over the open ocean away from the coast (thus guaranteeing an almost homogeneous flat reflecting surface), applications have developed over both land and ice. With its delay-Doppler mode promising a smaller instrument footprint, the processing and evaluation of altimeter data over ice and inland waters is now of equal concern. The work of the S3MPC here is divided into three categories - land ice, sea ice and inland waters - each of 
which requires its own dedicated processing to tease out information from the waveforms, and subsequently to validate those findings.

\subsection{Altimetry over Land Ice}

There have been challenges in acquiring surface topography measurements over ice sheets. The full width of the reception window recording the reflected waveforms is $\sim 60 \mathrm{~m}$, but the leading edge of the signal must lie within the central half of the window for there to be sufficient useful samples to allow accurate retracking. Over slowly-varying surface the positioning of this window is controlled solely by predictive software based on analysis of the previously received waveforms; this is closed loop processing and was used by the majority of conventional altimeters. However, this method fails to follow the sea surface when close to the coast (due to the earlier returns from land significantly above sea level), and it also fails to cope with land surfaces where the orography is steep. A particularly important example of this is the ice margins around Antarctica and Greenland; to ameliorate this problem, the SRAL can switch to open loop processing, whereby the tracker window uses an onboard digital elevation model (DEM) to predict where the reflecting surface should be. Particular care is required because for surface slopes $>1^{\circ}$ the point giving the nearest reflecting surface will not necessarily be at nadir.

Initially the altimeter was in open loop over all marine surfaces and over the ice sheets; however, this was subsequently changed on 6th Dec. 2016 to closed loop operation for Antarctica, Greenland and other Arctic islands, including the waters nearby. This was because the current method of open loop tracking does not track the surface as expected, and so requires further development and testing. At present the recovery of useful height data is much less than achieved by Cryosat-2 in SAR mode (Fig. 17). This is thought to be due to incorrect windowing of the echo within the extended Level 0 range window, often causing either the leading or trailing edge of the waveform to lie outside the final 128 bin window (Fig. 18). Comparisons are being made to the actual final implementation of the processing chain for Cryosat-2, which had evolved from the original design.
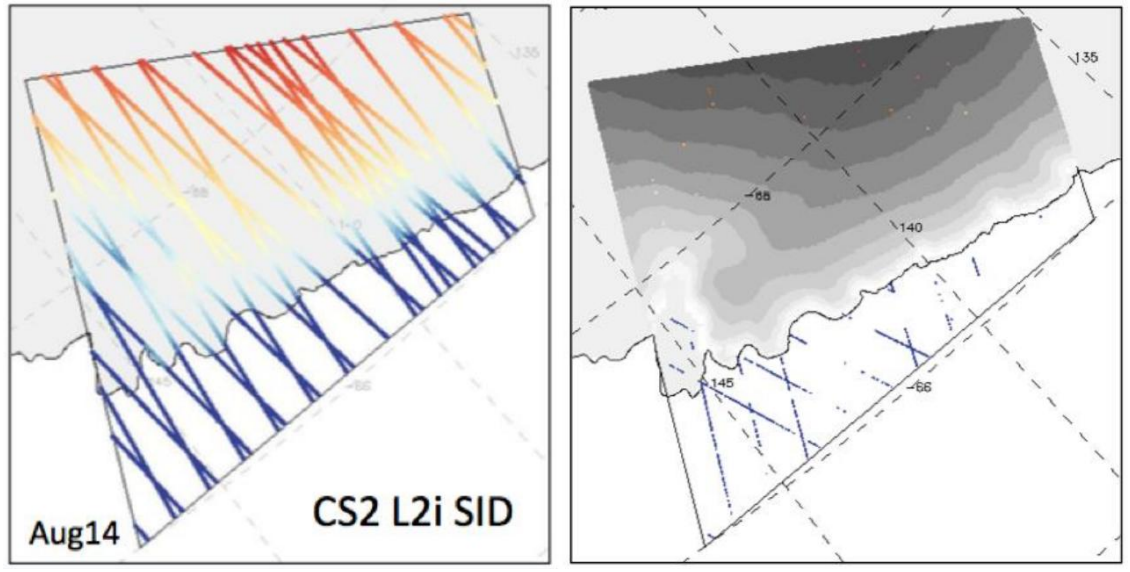

Figure 17. Recovery of useful altimeter data near the SPIRIT zone on the edge of the Antarctic margin. The key aspect is the number of locations for which a meaningful height (colour scale not shown) can be plotted. (left) Cryosat-2 data from August 2014 when data were collected in non-interferometric SID mode equivalent to that of S-3A. (right) Sentinel-3A data when operated in its Open Loop tracking mode. 

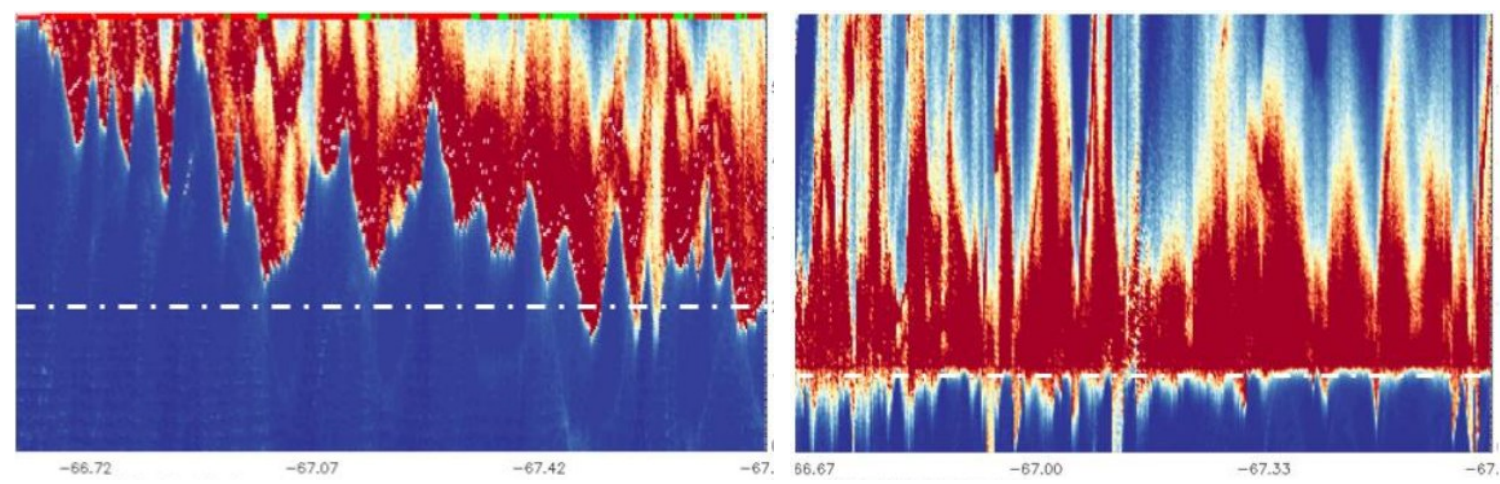

Figure 18. Comparison of (left) Sentinel-3A and (right) Cryosat-2 waveforms on similar tracks in the SPIRIT zone. The leading edge for Cryosat-2 is usually close to its nominal position (white dashed line) enabling all retracking processes to be implemented, whereas the window for S-3A fails to maintain the leading edge close to its nominal position, so approaches that are designed to expect the full waveform to be roughly centered will experience higher than expected failure rates and all retrackers will be affected by some waveform truncation.

\subsection{Altimetry over Sea Ice}

The challenges of operating in the regime of sea ice are different: some waveforms represent reflection from the ice floe and others are dominated by the signal from leads (narrow gaps of free water between the ice). The nature of the reflecting surface has to be determined from the differently shaped waveforms, and, although of very different shape, the returns from these surfaces have to be retracked in a consistent manner, either by a universal retracker, or by separate dedicated retrackers that have no range bias between their results.

Figure 19 shows the p.d.f. of freeboard estimates from Sentinel-3 and Cryosat-2 for the same sector of the Arctic Ocean. Once more, a processing methodology developed from that used for Cryosat-2 failed to produce the anticipated results, with S-3A showing a much broader histogram with a large proportion of negative values. It is believed that a significant cause of this anomalous behaviour is poor discrimination between returns floes and leads, which may be due to the definition used for pulse peakiness ${ }^{8}$ in the waveform classification procedure.

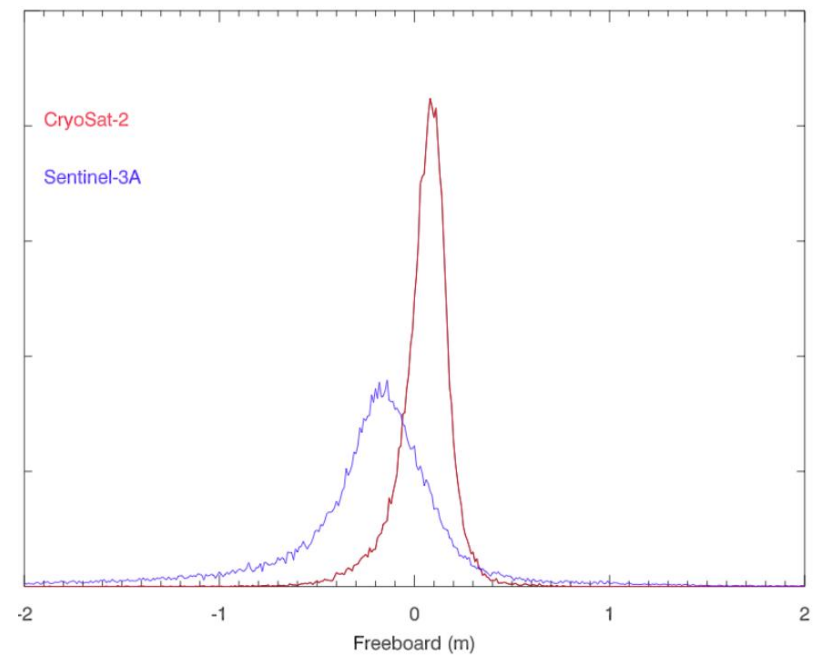

Figure 19. P.d.f. of freeboard calculated from Sentinel-3A (blue) and Cryosat-2 (red). for the same region of the Arctic Ocean [Freeboard is the height of the ice surface relative to that expected for the sea, derived by interpolation of the occasional measurements in leads.] 


\subsection{Altimetry over Rivers}

Altimetry data have been used to monitor river levels since thee of Geosat ${ }^{10}$, but the early studies were only possible with very wide rivers. SRAL has the advantages of both a much narrower along-track footprint than conventional altimeters, and the open loop setting to steer the reception window to match the expected elevation of the river. Therefore it is expected to provide useful height data over considerably more rivers and lakes than had been the case for previous missions. One of the exemplars that we use is the River Lot in southwestern France, with track 057 crossing it almost perpendicularly at a location where it is $\sim 150 \mathrm{~m}$ wide.

Figure 20 shows the surface elevation profiles derived during cycle 012 according to both the on-board tracker and ground-based retracking. A clear hyperbolic profile is shown for the data from the SAMOSA (ocean) retracker, as it ranged to the river, because it was the strongest reflecting point. Surprisingly there were no data for the OCOG (ice) retracker; this is believed to be due to the tracker not being applied if the data fail some quality tests. Subsequently processing has been adapted to always apply the OCOG algorithm, and to also set a flag if the waveform data had not passed all the quality thresholds.

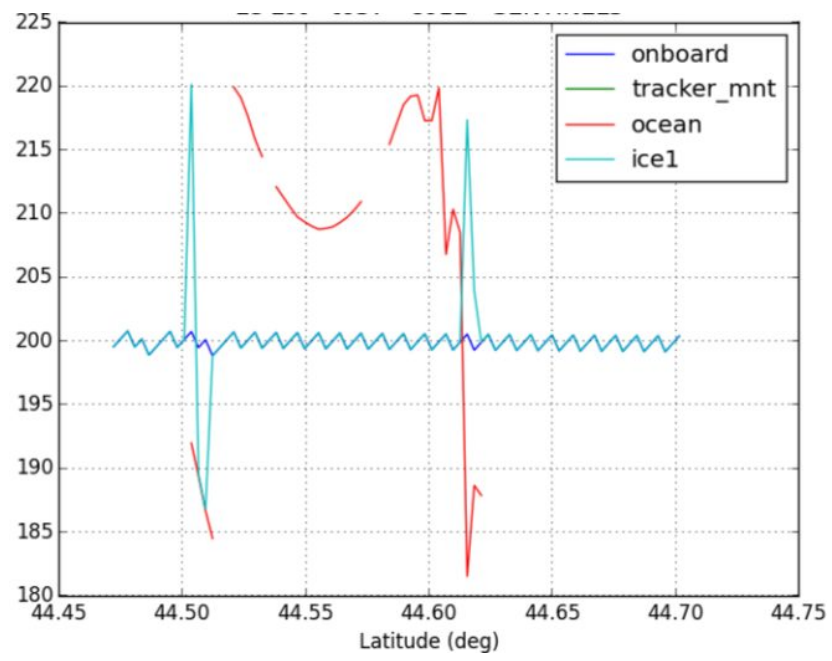

Figure 20. Elevation profiles for S-3A track 057 over the River Lot in southwestern France, with the coloured lines representing different tracking algorithms. The on-board tracker (dark blue) oscillates near a fixed value due to its setting, whilst the SAMOSA ocean retracker (red) shows a distinctive hyperbola centred on the point where it crosses the $150 \mathrm{~m}$ wide river. In this example, the OCOG retracker (light blue) failed to return any values.

\section{SUMMARY AND FUTURE PROGRESS}

With now more than a year's data available, a clear picture is arising of the performance of the Surface Topography instruments on Sentinel-3A. The monitoring of instrument temperatures and other characteristics has found a recognisable change in some of the parameters. In most cases it is sufficient to know these changes to sufficient accuracy to be able to correct for them in the on-ground processing. The rate of power loss in the emitted pulses was an aspect of concern (Fig. 2b), but found not to be critical for the achievement of the mission goals. For the MWR, the gain and noise injection temperature for the $36 \mathrm{GHz}$ channel (Fig. 4b) are more variable than expected; however, the records over the reference targets appear as stable as for any other radiometer in space (Fig. 6). The records for wind speed and wave height have improved through the various processing changes, but are still slightly biased with respect to a model that assimilates other altimeter data, and there are regional biases in the wet tropospheric correction that need to be understood.

Most of the analyses showed here used data with IPF v6.07 processing, and recently all the NTC data from mid-June 2016 onwards have been reprocessed to this standard. Figure 15 shows that the SSH and SWH records are almost at a stage where they can be combined with those from other altimeters. However, there remain a few issues with the ocean retracker (which produces the geophysical estimates from the waveform data), and a further reprocessing is envisaged for late 2017. Such a reprocessing is likely to subtly change some of the biases relative to other datasets; the operational 
agencies (such as weather forecasting centres) are likely to wait until the processing chain is fixed and all biases wellcharacterised before assimilating S-3A data routinely.

Sentinel-3A is the first altimeter mission to apply SAR processing over all surfaces, with the low level ground processing initially tuned for ocean applications; thus identifying and resolving the issues associated with its global remit have necessitated much more effort than for a purely ocean-focussed mission. A number of challenging issues have been found for work over the cryosphere, with S-3A's performance not initially matching that of Cryosat-2 (in SAR mode) as was anticipated. The amount of useful data over the ice sheet margins in particular has been approximately half of that expected, due to the Level 1 ground processing not being optimised for the rapidly-varying position of the waveform over sloping ice sheet terrain. The discrimination between radar waveforms over ice floes and leads has not been optimised yet, meaning that Arctic records of both sea level and ice thickness have been affected. Solutions to both the land ice and sea ice problems are being evaluated thoroughly before they can be implemented in a later processing run.

Sentinel-3B is due for launch in the second quarter of 2018, and much of the same analysis will be applied to that instrument, noting that although almost identical to S-3A there may be slight differences in performance. The assessment and calibration of S-3B should benefit from the existence of a $\sim 4.5$-month "tandem phase" when the two missions fly the same track only 30 seconds apart, permitting a close intercalibration.

\section{REFERENCES}

[1] Donlon, C. Berruti, B., Buongiorno, A., Ferreira, M.-H., Féménias, P. Frerick J. and co-authors, "The Global Monitoring for Environment and Security (GMES) Sentinel-3 mission", Rem. Sensi. Env. 120, 37-57 (2012). doi: 10.1016/j.rse.2011.07.024.

[2] Ruf, C., "Detection of calibration drifts in spaceborne microwave radiometers using a vicarious cold reference", IEEE Trans. Geosci. Remote Sens. 38, 44-52, (2000). doi: 10.1109/36.823900

[3] Ruf, C., "Characterization and correction of a drift in calibration of the TOPEX microwave radiometer", IEEE Trans. Geosci. Remote Sens. 40, 509-511, (2002). doi: 10.1109/36.992824

[4] Abdalla, S., "Ku-band radar altimeter surface wind speed algorithm", Mar. Geod. 35(S1):276-298, (2012). doi: 10.1080/01490419.2012.718676

[5] Mertikas, S.P.; Daskalakis, A.; Tziavos, I.N., Andersen, O.B., Vergos, G.S, Tripolitsiotis, A., Zervakis, V., Frantzis, X., and Partsinevelos, P., "Altimetry, bathymetry and geoid variations at the Gavdos permanent cal/val facility", Adv. Space Res. 51 (8), 1418-1437, (2013). doi: 10.1016/j.asr.2012.10.021

[6] Mertikas, S.P., Daskalakis, A., Frantzis, X., Tripolitsiotis, A., and Partsinevelos, P. "Preparatory works for the altimeter calibration of the Sentinel-3 mission using the dedicated calibration site in Crete and Gavdos", SPIE Symposium on Remote Sensing, Paper no. 8175-31, (2011).

[7] $\mathrm{Xu}, \mathrm{Y}$., and Fu, L.-L., "Global variability of the wavenumber spectrum of oceanic mesoscale turbulence", J. Phys. Oceanogr. 41, 802-809, (2011). doi: 10.1175/2010JPO4558.1

[8] Dibarboure, G., Boy, F. Desjonqueres, J.-D., Labroue, S. Lasne, Y., Picot, N., Poisson, J.-C., and Thibaut, P., "Investigating short-wavelength correlated errors on low-resolution mode altimetry", J. Atmos. Oceanic. Tech., 31, 1337-1362, (2014). doi: 10.1175/JTECH-D-13-00081.1

[9] Laxon, S., "Sea ice extent mapping using the ERS-1 radar altimeter", EARSeL Adv. in Rem. Sens. 3 (3), 112116, (1994).

[10] Koblinsky, C.J., Clarke, R.T., Brenner, A.C., and Prey, H., "Measurement of river level variations with satellite altimetry", Water Res. Res. 29 (6), 1839-1848, (1993). 